\author{
Антония Радкова \\ Софийский университет им. Св. Климента Охридского (София, Болгария)
}

\title{
ИЗУЧЕНИЕ РУССКОГО ЯЗЫКА В СЛАВЯНОЯЗЫЧНЫХ СТРАНАХ ЕВРОСОЮЗА
}

В последние десятилетия позиции русского языка в странах Центральной и Восточной Европы сильно изменились. От обязательного предмета до почти полного исключения из школьной программы, от языка, который изучали все, до редкого и потом снова до востребованного на рынке языка - в изучении русского языка наблюдаются интересные тенденции. Причины, влияющие на эти перемены, разнообразны: экономические, политические, культурные, языковые. Современная жизнь требует владения иностранными языками и при выборе иностранного языка мы руководствуемся различными факторами: насколько этот язык будет нам полезен в нашей работе или в проведении свободного времени; каково наше отношение к носителям данного языка и к стране, в которой говорится на данном языке; будет ли трудно изучать этот язык и за какое время мы сможем достичь желанного уровня владения языком?

В данной статье проведен анализ изучения русского языка в 5 славяноязычных странах Евросоюза: в Болгарии, Чешской Республике, Польше, Словакии и Словении. Мы исключили Хорватию, так как отсутствуют данные Евростата и Евробарометра, которые использованы для анализа, по этой стране. Мы протестируем несколько гипотез на связь с мотивацией изучения русского языка в славяноязычных странах - влияет ли на мотивацию и в какой степени: близость языков; спрос на русский язык на рынке труда; интенсивность экономических связей и туризма; отношение к стране изучаемого языка, к носителям русского языка, к русской культуре и другие.

Прежде чем приступить к анализу этих гипотез, коротко представим данные Евростат об изучении русского языка в школах. 


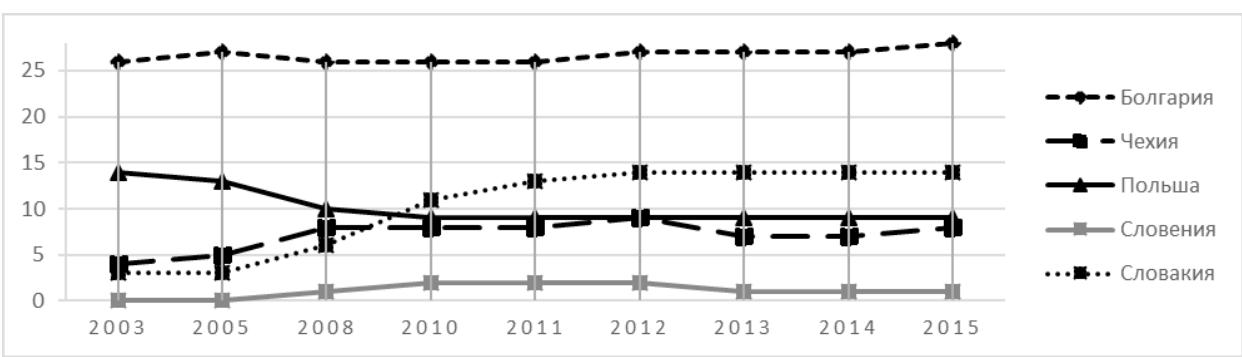

Табл. 1. Изучение русского языка с 5 по 8 класс (в процентах от общего числа учеников)

Анализируя представленные статистические данные, можно сделать следующие выводы: в Словакии и Чешской Республике наблюдается увеличение числа учеников, в Болгарии наблюдается хотя и незначительное, но уменьшение, а в Польше в 2008 был спад, затем в 2012 увеличение и сейчас снова уменьшение. «Увеличение количества учеников, обучающихся русскому языку в Чехии, связано в первую очередь с введением второго иностранного языка как обязательного предмета в основных школах. Опыт преподавателей показывает, что русский язык часто выбирают слабые ученики, которые с трудом справляются с первым иностранным языком, ожидая при этом определенных послаблений при обучении славянскому языку» (Корычанкова 2016: 90). В Словакии обязательное изучение второго иностранного языка введено еще раньше, в Болгарии, наоборот, его изучение до 9 класса является факультативным, и большая часть учеников изучает только один язык, и это в основном английский.

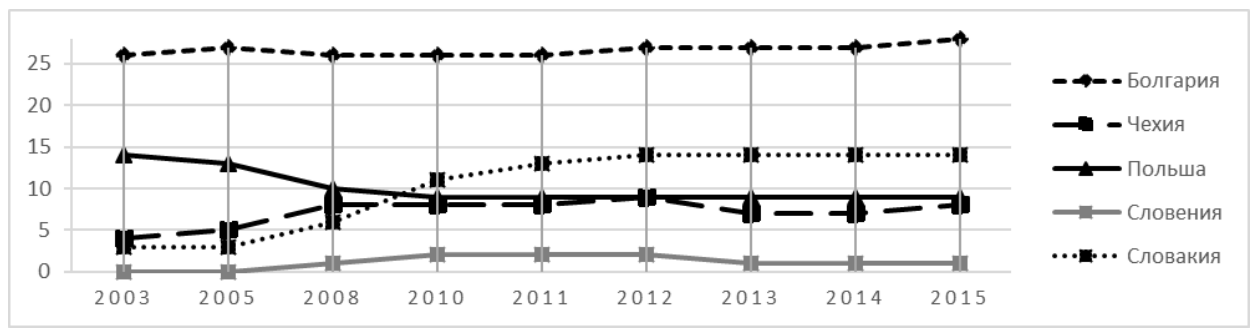

Табл. 2. Изучение русского языка в старших классах (в процентах от общего числа учеников)

В старших классах изучение русского языка задерживается примерно на одном и том же уровне за исключением Словакии, где наблюдается видимое увеличение: с 2009 по 2015 - вдвое, а с 2003 по 2015 - втрое.

Обобщение статистических данных изучения русского языка в системе школьного образования позволяет выявить несколько тенденций. Во-пер- 
вых, изучение русского языка переживает заметные изменения в исследуемых славяноговорящих странах. Нельзя подвести эти страны под общий знаменатель, так как тенденции в них разнонаправленные: наблюдается одновременно увеличение количества учеников, изучающих русский язык (Словакия, Чехия), наблюдается также и легкий спад (в Польше в старших классах, в Болгарии - в 5-8 классах).

Основную роль при выборе иностранного языка в школе играют родители, школьники делают выбор в пользу того или иного языка под их влиянием. Поэтому мы считаем важным соотнести статистические данные изучения русского языка в школах с данными социологическими опросов. Ответы на вопрос «Какие два языка вы считаете наиболее необходимыми а) для вас и б) для будущего развития ваших детей?» показывают четыре типа тенденций отношения к русскому языку: постоянное отношение (Болгария), незначительное повышение интереса (Чешская Республика и Словения), значительное повышение интереса (Словакия) и снижение интереса (Польша) (Eurobarometer 2001: 36, Eurobarometer 2006: 32-33, Eurobarometer 2012: 70-79). Динамика изменения отношения к русскому языку и мотивации его изучения и пользы на будущее, которые показаны данными социологических опросов, не могут не вызвать у читателя вопрос: почему развитие отношения к русскому языку так сильно отличается в разных странах? Почему в одних государствах, где изучение русского было близко к нулю, теперь появляется, хотя и незначительный, интерес к нему (Словения), в других интерес задерживается на одном и том же уровне: относительно высоком по сравнению с другими странами (Болгария) и среднем (Чешская Республика), а в некоторых странах интерес к изучению русского понизился (Польша)? Чешские социолингвисты Неуступни и Неквапил приводят следующие причины выбора русского в качестве иностранного языка: легче изучать славянский язык; достаточно большое количество учителей могут преподавать русский язык; идеологическая оппозиция русскому языку медленно исчезает, в то время как экономические отношения с Россией и другими странами бывшего Советского Союза становятся все более важными. По их мнению близость языков является важным фактором выбора: «русский язык также делает возможной семикоммуникацию (особый вид общения между носителями близкородственных языков, когда каждый из собеседником говорит на родном языке, а воспринимает язык собеседника) с носителями других славянских языков» (Неуступни, Неквапил 2009: 131).

Изучение родственного или близкородственного иностранного языка всегда рассматривается как более легкое. Ниже мы попробуем проанализировать влияние степени близости болгарского, чешского, польского, словацкого и словенского языков с русским на мотивацию его изучения. Процент близкой лексики в списке Сводеша между русским и соответственно болгарским составляет $74 \%$, чешским $-74 \%$, польским $-77 \%$, словацким $-74 \%$ 
и словенским 74\% (Дьячок 2002: 10). Степень близости между языками может определяться и по уровню взаимопонимания между носителями этих языков: 1) свободное общение; 2) отдельные случаи взаимонепонимания; 3) отдельные знакомые слова и фразы; 4) общение невозможно, но при изучении обнаруживаются общие слова и правила; 5) родство языков может обнаружить только специалист (Яхонтов 1980: 151-154). Взаимопонимание между анализируемыми языками находится на третьем уровне в данной классификации: отдельные знакомые слова и фразы.

Сопоставление социологических данных отношения к изучению русского языка (см. выше) показывает, что близость языков сама по себе не вызывает желания изучать язык. Если бы сходство в языках являлось ключевым фактором, то тогда интерес к русскому языку был бы самым высоким в Польше, а интерес в Словении был бы на уровне Болгарии, Чешской Республики и Словакии. То, что близость языков не играет существенной роли, показывает интерес к русскому языку в Словении, Хорватии, Бывшей югославской Республике Македонии, а также спад интереса к изучению русского языка в Сербии (Арефьев 2012: 233-242). Подобным образом интерес к изучению родственного французского языка достаточно невысок в странах Латинской Америки, несмотря на близость испанского или португальского к французскому языку.

Важные при изучении родственных языков явления трансфера, интерференции, когнатов, ложных когнатов и т.д. хорошо описаны. Но сравнение очень близких языков имеет и еще одну особенность - это психологическое восприятие «малых различий». Гипотеза «нарциссизма малых различий» восходит к Зигмунду Фрейду: как утверждает психоанализ, каждая близкая связь «оставляет осадок противоположных враждебных чувств... Родственные племена недолюбливают друг друга, южный немец не выносит северного немца, англичанин злобно говорит о шотландце, испанец презирает португальца» (Фрейд 1926). Когда языки очень близки, различия в них могут вызывают насмешку и неприятие. В близкородственных языках много элементов, которые сохранили сходство формы, но изменили значение, и одно и то же слово или словосочетание имеет разные значения. Обычно это вызывает смех или в лучшем случае удивление. Чем ближе языки, тем больше таких вызывающих смех или удивление явлений. «Нарциссизм малых различий» вряд ли играет ключевую роль при выборе иностранного языка, но так или иначе это явление следует учитывать при изучении близкородственного языка.

Итак, рассчитывать на близость русского языка и предполагаемую «легкость» в его изучении нельзя. Кроме того, выбравшие изучать русский язык из-за его «легкости» могут оказаться разочарованными и потерять уверенность в успешности результатов обучения и интерес к русскому языку.

В последние десятилетия мотивация изучения русского языка все чаще объясняется прагматическими выгодами, которые обучающиеся надеются 
извлечь в результате усвоения иностранного языка. Такую мотивацию называют инструментальной или прагматической. Инструментальность отражает идею о том, что для большинства изучающих иностранный язык движущей силой является ожидаемая польза (Dörnyei 2013: 87). Если использовать термин французского социолога Пьера Бурдьё, знание языка - это вид лингвистического капитала. Понятия «лингвистический капитал» и «лингвистический рынок» в социологии Бурдьё рассматриваются как часть экономики лингвистических взаимодействий (Бурдьё 2007). Например, человек, владеющий иностранным языком, обладает лингвистическим капиталом, который несет ему престиж, положение в обществе, бо́льшие возможности на рынке труда. Этот капитал, по мнению Бурдьё, можно разменивать на другие виды капитала: экономический (найти работу, получить бо́льшую зарплату), социальный (иметь лучшее положение в социальной группе и в обществе) и культурный капитал (использовать культурные ресурсы, доступ к которым дает владение языком).

Знание языков увеличивает перспективы найти лучшую, интересную и хорошо оплачиваемую работу. Для определения востребованности русского языка на рынке труда в славяноязычных странах Евросоюза нами были проанализированы данные наиболее популярных сайтов для поиска работы: www.jobs.bg, www.jobs.cz, www.pracuj.pl, www.profesia.sk (данные для Польши, Чешской Республики и Словакии даны по Beblavý (Beblavý, Fabo, Lenaerts: 2016); для Болгарии данные были анализированы по тем же критериям автором данного исследования; данные по Словении отсутствуют). Анализ показывает, что русский язык объявлен как необходимый для работы в около двух процентах объявлений в Болгарии и Польше и в менее одного процента объявлений в Чешской Республике и Словакии. Во всех государствах востребование русского намного меньше востребованности английского. Количество объявлений с требованием или рекомендацией знать английский в среднем около $50 \%$, немецкий - около $12 \%$, французский - около $2 \%$.

При всей условности анализа сайтов поиска работы, которые не охватывают весь рынок труда (например, сюда не входят рабочие места в госсекторе или в сфере образования), эти данные могут дать информацию об общей тенденции спроса на русский язык. Информацию о востребованности русского языка на рынке труда (для каких профессий, в каких областях экономической жизни, в комбинации с какими другими умениями необходим русский язык) следует учитывать при планировании и проведении обучения русскому языку. «Хорошее знание двух иностранных языков в настоящее время является необходимостью, причем знание т. н. западного (английский, немецкий, испанский и др.) и знание русского языка представляется для выпускников средних школ и вузов большим преимуществом на рынке труда. Молодые люди, потенциальные студенты, не воспринимают русско-чешские отношения под углом зрения исторических коннотаций, а родители, часто 
под воздействием финансово-экономических факторов, прибегают к более прагматичному взгляду на будущую профессиональную ориентацию своих детей» (Корычанкова 2016: 90).

Количество русских туристов в стране также может объяснить рост или спад интереса к русскому языку. Проанализировав статистические данные, А. Павленко заключает, что почти все города и местности, где русский как туристический язык используется наряду с английским, находятся в странах, наиболее популярных среди россиян. По ее мнению коммодификация русского языка, то есть превращения языков в товар (commodity) в эпоху глобализации, и рост спроса на русский язык в связи с увеличением турпотока не отражается на статистике изучения русского языка, так как «спрос на русский язык часто удовлетворяется за пределами традиционной образовательной системы... Изучающие русский язык таким образом часто остаются вне поля внимания статистических исследований изучения русского языка за рубежом» (Павленко 2016: 24-29).

При описании сегодняшнего состояния, главных нужд и проблем преподавания русского языка исследователи учитывают и исторические факторы. Исследование современных тенденций изучения русского языка возможно только с учетом и исторической перспективы. «Во время Польской Народной Республики обучение сталкивалось с неким сопротивлением со стороны части учеников. Отражалось это на результате преподавания: большая часть учеников осваивала необходимый минимум, считая обучение русскому языку русификацией» (Чахор 2011: 11).

Образ страны изучаемого языка является важным мотивационным фактором при выборе языка. Понятие образа России включает «совокупность знаний и представлений о стране, включающих политические, социально-экономические, исторические составляющие, а также знания и представления о культуре (литературе, музыке, кино и т.д.), бытовой жизни, национальном характере жителей страны» (Лукина 2008: 6). Историческая составляющая играет важную роль, так как большинство славяноязычных стран находятся в географической близости с Россией (кроме Словении), и создали многовековые, в некоторых случаях противоречивые отношения с ней. Важное влияние на отношение к любой стране оказывает также благосостояние, цивилизационное развитие и попросту богатство страны. Чем выше валовой продукт, «производимый» на данном языке, тем выше заинтересованность к изучению данного языка. Кроме того, при анализе отношения к культуре и носителям русского языка следует учитывать и связь культуры с религией, в особенности для стран, где религия играет важную роль, как, например, в Польше. Люди чувствуют более близкими людей, исповедующими ту же или близкую религию (Taras 2014: 717). Православными среди жителей исследуемых государств являются болгары, во всех остальных странах большинство жителей являются католиками. 
По мнению экспертов-международников страны Евросоюза делятся на пять категорий в зависимости от их отношения к России. Болгария, Словакия и Словения попали в разряд «дружеских прагматиков», «поддерживающих близкие отношения с Россией и ставящих свои деловые интересы выше политических целей». К этой группе относятся также Австрия, Бельгия, Финляндия, Венгрия, Люксембург, Мальта, Португалия. «Холодные прагматики фокусируют свое внимание на деловых интересах, но в меньшей степени, чем другие, боятся высказываться по поводу поведения России в сфере прав человека и других вопросах», - это Чехия, а также Дания, Эстония, Ирландия, Латвия, Нидерланды, Румыния, Швеция и Соединенное Королевство. Польша и Литва определены как «новые бойцы холодной войны» за то, что «имеют открыто враждебные отношения с Москвой и намерены использовать право вето, чтобы заблокировать переговоры ЕС с Россией» (Leonard, Popescu 2014: 36-50). Кроме этих групп, в которые входят интересующие нас славяноязычные государства, эксперты определяют еще две группы: «троянские кони» (Греция и Кипр) и стратегически партнеры (Германия, Франция, Италия и Испания). Опрос Евробарометра в 2016 г. показал, что выше всего положительное отношение к России среди славяноязычных стран ЕС в Болгарии $(72 \%)$, Словакии (61\%) и Словении (45\%). Наименьшее число позитивно относящихся к России в Польше $(27 \%)$ и Чешской Республике $(39 \%)$ (Eurobarometer 2016: 74). Отношение к России коррелирует с указанным в начале статьи желанием изучать русский язык во всех странах, кроме Словении: чем выше позитивное отношение, тем выше интерес. На небольшой интерес к изучению русского языка в Словении оказывает влияние вероятно и отсутствие традиции изучения русского языка и подготовленных кадров.

\section{ЗАКЛЮЧЕНИЕ}

Анализ данных из различных областей: статистических и экономических показателей, результатов социологических опросов, исследований филологов, методистов и международников, позволяет сделать следующие выводы.

На желание изучать русский язык оказывают влияние много факторов. «При выборе русского языка в качестве иностранного языка учащиеся руководствуются, как правило, не одним мотивом, а совокупностью мотивирующих факторов. Образ России при выборе и изучении русского языка является, хотя и не единственным, но, безусловно, одним из ведущих мотивов» (Лукина 2008: 19). В Польше наиболее сильная зависимость между образом страны и желанием изучать русский язык. В Чешской Республике 
эта зависимость не так сильна и хотя в стране существует негативное отношение к России, в отношении к изучению русского языка в последние годы наблюдаются положительные тенденции. Это соответствует определению Чешской Республики как прагматика, для которого основными являются деловые интересы. Болгария и Словакия тоже подтверждают свои образа «дружественных прагматиков». Словения, наоборот, сочетает положительный образ России с низкой мотивацией.

С изменением социальной среды неизбежно меняются мотивы выбора русского языка и его изучения. Экономические факторы (торговые отношения, турпоток из России) формируют спрос на русский язык на рынке труда и соответственно на мотивацию предпочтения русского языка. В отличие от экономики близкородственность языков и предполагаемая легкость в изучении русского языка оказывает несущественное влияние на мотивацию.

Важное значение для повышения доли изучающих русский язык является и политика многоязычия, принятая Советом Европы и Евросоюзом. В соответствии с ней во всех исследуемых государствах изучаются в обязательном порядке два иностранных языка. Чем раньше начинается изучение второго иностранного языка, которым часто является именно русский язык, тем больше количество изучающих этот язык.

\section{Библиография}

Арефьев А. Л. (2012), Русский язык на рубеже XX-ХХІ веков, Москва.

Бурдьё П. (2007), Соииология соииального пространства, Санкт-Петербург.

Дьячок М. (2002), О методах генеалогической классификации языков. Материалы третьей научной конференции преподавателей и студентов, Новосибирск, с. 105-110.

Корыченкова С. (2016), Система подготовки учителей русского языка в Чешской Республике - современное состояние, задачи и перспективы направления, «Новая русистика», № 2 / 2016, с. 89-98.

Лукина Я. В. (2008), Зависимость мотивачии при выборе и изучении иностранного языка от образа страны изучаемого языка, Санкт-Петербург, www.zlat-edu.ru/CatalogImages/File/ lukina.doc

Павленко А. (2016), Русский язык как лингва франка в сфере обслужсивания, Мир русского слова, 1, с. 23-32.

Фрейд 3. (1926), Психология масс и анализ человеческого «Я», Москва.

Чахор Р. (2011), Преподавание русского языка в Польше: исторический опыт, состояние, перспективы, Rocznik Instytutu Polsko-Rosyjskiego 1 (1), с. 7-16.

Яхонтов С. Е. (1980), Оиенка степени близости родственных языков, [в:] Теоретические основы классификации языков мира, Москва, с. 150-183.

Beblavý M., Fabo B., Lenaerts K. (2016), The Importance of Foreign Language Skills in the Labour Markets of Central and Eastern Europe. Centre for European Policy Studies.

Dörnyei Z., Ushioda E. (2013), Teaching and researching: Motivation, London.

Eurobarometer (2001), Candidate Countries Eurobarometer, European Commission. 
Eurobarometer, Special (2006, 2012), Europeans and their Languages, European Commission.

Eurobarometer, Special (2016), Future of Europe, European Commission.

Eurostat (2017), Pupils by education level and modern foreign language studied, http://ec.europa. eu/eurostat/web/education-and-training/data/database

Leonard M., Popescu N. (2007), A power audit of EU-Russia relations, London.

Neustupny J. V., Nekvapil J. (2005), Language management in the Czech Republic, [в:] Language planning and Policy in Europe, c. 16-201.

Taras R. (2014), Russia Resurgent, Russophobia in Decline? Polish Perceptions of Relations with the Russian Federation 2004-2012, Europe-Asia Studies, 66:5, c. 710-734.

Antonia Radkova

\section{STUDY OF THE RUSSIAN LANGUAGE IN THE SLAVIC LANGUAGE COUNTRIES OF THE EUROPEAN UNION}

(Summary)

The purpose of this article is to analyze the motivation to learn Russian language in Slavic countries of European Union. The paper describes factors that strongly influence the choice and the process of Russian language learning. A meta-analysis was carried out using data from statistics, sociology, economics, and linguistics. The results showed that many factors such as economic, political, cultural, linguistic, and religious affect motivation to varying degrees. The most important factor is the image of Russia among the country citizens.

Keywords: learning Russian language, motivation, Slavic countries of the European Union

\section{ИЗУЧЕНИЕ РУССКОГО ЯЗЫКА В СЛАВЯНОЯЗЫЧНЫХ СТРАНАХ ЕВРОСОЮЗА}

(Резюме)

Цель настоящей статьи - проанализировать мотивацию изучения русского языка в славяноязычных странах Европейского союза. Исследование описывает причины, которые оказывают влияние на выбор и процесс изучения русского языка. Был проведен метаанализ с использованием данных из области статистики, социологии, экономики и лингвистики. Результаты показали, что множество факторов влияют на мотивацию в различной степени: экономические, политические, культурные, лингвистические, религиозные. Ключевым среди факторов является образ России в глазах жителей соответствующей страны.

Ключевые слова: изучение русского языка, мотивация, славяноговорящие страны Евросоюза 